Journal of Advanced Research in Materials Science

\title{
Polyimide Based-Carbon Membrane: Effect of Pyrolysis Environment
}

\author{
Norazlianie Sazali ${ }^{1,2,}{ }^{*}$, Ramli Junid ${ }^{1}$, Januar Parlaungan Siregar ${ }^{1,2}$ \\ 1 Structural Performance Material Engineering (SUPREME), Faculty of Mechanical \& Automotive Technology Engineering, Universiti Malaysia \\ Pahang, 26600 Pekan, Pahang, Malaysia \\ 2 Centre of Excellence for Advanced Research in Fluid Flow (CARIFF), Universiti Malaysia Pahang, Lebuhraya Tun Razak, 26300 Gambang, \\ Kuantan, Pahang, Malaysia
}

\section{ABSTRACT}

Tubular carbon membrane was prepared from BTDA-TDI/MDI (P-84) polyimide as a main precursor that blends with nanocrystalline cellulose (NCC) through controlled pyrolysis condition. The effects of the final pyrolysis environment on $\mathrm{O}_{2}$ and $\mathrm{N}_{2}$ permeation levels were studied. By manipulating pyrolysis conditions during the process of pyrolysis with rate of heating at $3^{\circ} \mathrm{C} / \mathrm{min}$, a final temperature of $800^{\circ} \mathrm{C}$ and a stabilization temperature of $300^{\circ} \mathrm{C}$, the performance of the carbon tubular membrane can be regulated based on a review of previous studies. The control of pyrolysis environment (helium, argon, and nitrogen gases) through the quality of carbon membranes influenced the permeation of gas properties themselves. By applying Ar gasses as a pyrolysis environment throughout the process of heat treatment, a better performance in gas separation was found. Single gas permeation tests of $\mathrm{O}_{2}$ and $N_{2}$ were performed to examine the transport mechanism in the process of carbon membrane separation. The PI/NCC carbon membrane that undergoes Ar environment showed the most impressive finding with the highest selectivity of $8.23 \pm 3.27$ for $\mathrm{O}_{2} / \mathrm{N}_{2}$ 213.56 $\pm 2.17 \mathrm{GPU}$ permeance of $\mathrm{O}_{2}$.

\section{Keywords:}

Carbon membrane, Thermal soaking time, BTDA-TDI/MDI (P-84) polyimide,

\section{Introduction}

Generally, through thermal decomposition of the polymer precursor membrane, carbon membranes are formed [1]. This variety of materials used are thermally stable attributed to their strong oxidative, disordered $\mathrm{sp}_{2}$ hybridized structure of carbon piece and disorientation of angle. In addition, the analysis indicated high permeability and carbon membrane selectivity without losing efficiency relative to polymer membrane selectivity [2]. Because of the definite and disordered structures of carbon material are differing from zeolites [3]. In gas separation applications, carbon materials provide perfect pore size dispersal that offers homogeneous defect-free membranes. Though substantial work has been recorded since the advent of carbon membranes, the need to develop these membranes gas separation properties remains crucially significant to turn out to be

\footnotetext{
* Corresponding author.

E-mail address: azlianie@ump.edu.my (Norazlianie Sazali)
} 
feasible for practical applications [4]. Pyrolysis conditions are the major drivers that is impacting as well as the composition of the membrane and the properties of gas permeation during pyrolysis. So far as carbon membranes involve, one of the accomplishments of researchers working in this field is by analysing on pyrolysis environment.

Potential in achieving higher performance of gas separation has spurred membrane researcher into the direction of performing carbon membrane by modifying multiple method parameters with improved efficiency of the existing gas separation process $[5,6]$. At the final temperature, one of the parameters that would influence the properties of membrane transport is the pyrolysis environment (He, $N_{2}$, and $\mathrm{Ar}$ ). Past research done by Lua and $\mathrm{Su}$, by controlling pyrolysis temperature, heating frequency, and pyrolysis environment, they have prepared carbon membrane from Kapton ${ }^{\circledR}$ polyimide [7]. A recent study has shown that pyrolysis conditions have a huge impact on the permeation properties of carbon membrane gas [8]. The rate of gas permeation was reported to be raised by adjusting the environment of pyrolysis to inert. As stated by Suda and Haraya, under Ar or in vacuum, dense carbon membrane films will be generated by polyimide Kapton ${ }^{\circledR}$ [8]. As stated by Geiszler, by using 6FDA / BPDA-DAM, the carbon membranes asymmetric hollow fibers pyrolyzed under various gas conditions $\left(\mathrm{Ar}, \mathrm{He}\right.$ and $\mathrm{CO}_{2}$ ) have shown insignificantly different outcomes for the separation of $\mathrm{O}_{2} / \mathrm{N}_{2}$ and $\mathrm{H}_{2} / \mathrm{N}_{2}$. [9]. Furthermore, they discovered that the efficiency of the carbon membrane quality was credited to the inert gas purge flow rate and was demonstrated in their study that the carbon membranes removed $200 \mathrm{~cm}^{3} / \mathrm{min}$ had a 700 times higher flux compared to the 20 $\mathrm{cm}^{3} /$ min samples purged. Additionally, inert gas flows will include superior heat transfer that can quicken the process of pyrolysis. Relative to the vacuum environment, it will create more transparent porous structure. However, subject to further reaction at high temperature, the amorphous membranes will contract [10].

PI-copolyimide was used as the primary precursor in this study because of the potential of polymers to sustain high temperatures throughout the pyrolysis cycle [11]. This material displays excellent gas selectivity, which for polymer membranes is the most impressive ever reported [12]. Polyimide BTDA-TDI / MDI (P-84) does not change its form and will not pass through a melting stage; thus, as a precursor to the advancement of carbon membranes, they are consistently preferred. This material also demonstrated superior gas selectivity for polymer membranes [13]. This polymer is a hopeful alternative for gas separation, and due to its compound and physical properties, it is ideal to be used as a main alternative for carbon membrane production. Recently, from recycled newspaper nanocrystalline cellulose (NCC) was able to synthesize [14]. These materials are vastly developed in the nanotechnology industries due to their biodegradability. Additionally, the main interest of the NCC is to use its rod-like shape and low temperature to decompose. Like microstructure additives, it would be easy to split the NCC nanostructure in the chain of polymer [15]. There is still a lack of scientific work related to the environment during the heating process, based on the study published [16]. This research will therefore focus solely on preparing and characterizing PI / NCC polymer mixtures with manipulation of environment conditions. In this analysis, the quality of tubular carbon membrane gas separation will be assessed using $N_{2}$ and $O_{2}$ as test gasses to comprehend the connection amongst the pore structure and the carbon membrane preparation state. The terminology of the resulting carbon membrane for pyrolysis environment is referred to as $\mathrm{CM}-\mathrm{He}$, $\mathrm{CM}-\mathrm{Ar}$, and $\mathrm{CM}-\mathrm{N}_{2}$. 


\section{Experimental Section}

\subsection{Materials}

The performances of pyrolyzed membranes are affected by molecular structure of polymer precursor. Polyimide is one of the precursors of polymers due to its superior permeating diffusiveness and strong molecular sieving properties. Pellet-shaped polyimide (PI) (P84, Merck) has been used as the primary membrane producing material. N-methyl-2-pyrrolidone (NMP, Sigma Aldrich) been used as a solvent to remove polymer without further purification. At present, nanocrystalline cellulose (NCC) is not available on the market and was previously prepared in our study [17]. Shanghai Gongtao Ceramics Ltd. supplied commercial tubular ceramics (outer diameter: $13 \mathrm{~mm}$, internal diameter: $11 \mathrm{~mm}$, porosity: 40-50 percent, average pore size: $0.2 \mu \mathrm{m}$.) The $8 \mathrm{~cm}$ long membrane support is made of titanium dioxide $\left(\mathrm{TiO}_{2}\right.$ ) (average particle size: $4.5-5.5 \mathrm{~mm}$ ) layered on the support's inner surface with zirconium dioxide $\left(\mathrm{ZrO}_{2}\right)$ (average particle size: 2-3 nm).

\subsection{Preparation of Carbon Membrane}

Carbon membrane was processed by 15wt BTDA-TDI / MDI (P84) dope solution was dissolved as a solution in NMP after drying in an oven at $50^{\circ} \mathrm{C}$ for 24 hours. Slowly adding NCC to the mixture and stirred it slowly until the solution become homogenous. The polymer powder of P84 was added to the solvent and continuously mixed at 600 rotational per minute (rpm) until all polymer was fully dissolved. The dope was then ultrasound before the dip-coating process to eliminate potential bubbles contained in the solution. For 15 minutes, the reinforcement for the ceramic tube was plunged into the dope, then cooled for 24 hours at room temperature. To prevent some solvent from flowing in the supply, both ends of the ceramic pipe reinforcement are properly fastened. To remove the presence of pinholes in the membrane structure, the dip-coating process was repeated twice. The prepared polymer membrane then was dried for a day at $80^{\circ} \mathrm{C}$, soaked in methanol for 2 hours and dry for 24 hours at room temperature. Such measures have been repeated twice before the heating cycle. The polymer membranes were subsequently placed in a Carbolite wire wound tube furnace (Model: CTF 12/65/550) for heat treatment. The furnace pipe size is about $75 \mathrm{~cm}(60 \mathrm{~cm}$ heating zone) and the diameter is about $12 \mathrm{~cm}$. The membranes are added by heating up the membrane with a stabilization procedure up to $300^{\circ} \mathrm{C}$ and further carbonizing up to $800^{\circ} \mathrm{C}$ at $3^{\circ} \mathrm{C} /$ min thermal rate. The environment of pyrolysis was changed by saturating the furnace tube with various gasses such as argon, helium, and nitrogen while holding the thermal soak time at 120 minutes. After each heating cycle has been completed, the preparation of membranes should be cooled at room temperature naturally. Nonetheless, a collection of unsupported tubular carbon membranes was prepared for characterization purposes using the similar method.

\subsection{Pure Gas Permeation Measurement}

Membrane quality can be categorized into two significant constraints that are selectivity and permeance. The carbon membrane was tested using a method of internal gas permeation. The system contains of flexible hose, soap bubble meter, permeation tube, lock, pressure regulator. With a length of $14 \mathrm{~cm}$, the $8 \mathrm{~cm}$ carbon tubular membrane was mounted inside the stainless steel tubular frame. During the test, the membrane was fitted with rubber O-rings to prevent leakage. At 8 bars of transmembrane pressure, $\mathrm{N}_{2}$ and $\mathrm{CO}_{2}$ was fed separately into the module. The membrane's permeance and selectivity are determined using the equations stated in the study that was done before [18]. The word selectivity is recognized as fast gas to slow gas permeation ratio. The 
volumetric flow rate of the gas permeate were determined at room temperature with a reading of $1.0 \mathrm{ml}$ by the soap bubble flow meter. This test of permeation has been replicated with two different samples of the membrane. It was found that the high selectivity carbon membrane was created by controlling the pyrolysis environment. The gas permeability of two discrete gasses of varying molecular sizes; $\mathrm{O}_{2}$ (3.30) and, $N_{2}$ (3.80) was determined at a feed pressure of 8 bar by the resulting carbon membranes formed from different pyrolysis conditions.

\section{Results and Discussion}

The difference in the rate of permeation of gas and molecular solvent extraction properties are indicators of changes in structure of porous membrane resulting from the use of various inert environments during pyrolysis [19]. The production of gaseous products formed during the phases of decomposition is caused due to the pores. For instance, $\mathrm{CO}_{2}$ gas will possess higher permeances compared to $\mathrm{He}$ gases even though $\mathrm{He}$ molecular size are much smaller, indicating another transport mechanism for $\mathrm{CO}_{2}$ 's operation. The $\mathrm{CO}_{2}$ gas could have been absorbed to the surface of the pore, followed by the surface diffusion of the absorbed $\mathrm{CO}_{2}$ molecules throughout the pore. Pyrolysis in inert environment such as helium gas flow can result in the reaction into the decomposition of acceleration resulting in a high permeation level of gas compared to all of that prepared under Ar and $N_{2}$ [20]. During the pyrolysis cycle, heat and mass transfer will increase, creating more porous structure. Carbon membrane's transport properties interact with pyrolysis environment. For example, inert gases react and adhere to the reactive areas of the carbon membranes during the pyrolysis process in order to create ultra-micropores [21]. Nonetheless, the slit-like pore structure is formed because of the deposition of amorphous carbon consisting of unevenly packed sheets of $\mathrm{sp}_{2}$ hybridized carbon. The gas permeance of the processed carbon membranes approaches $\mathrm{O}_{2}>\mathrm{N}_{2}$ sequence, which is consistent with the molecular sieving mechanism [22]. The co-existing of ultramicropores and large pores that responsible for adsorption sites which are the basic mechanism in molecular sieving. With that, the selectivity will increase, thus lower the permeability.

\subsection{Effect of pyrolysis on gas permeation properties}

According to Favvas and co-workers, the amount of carbon membrane pore produced under the environment of helium is more porous than membrane produced under $\operatorname{Ar}$ and $N_{2}$ at the same temperature [23]. Because of the small difference between the two molecular sizes, the carbon membranes acquired from the $\mathrm{Ar}$ and $\mathrm{N}_{2}$ gas environment show only different results in gas permeances; Ar: $3.40 \AA, N_{2}: 3.64 \AA$. . Table 1 shows Oxygen performance of carbon membranes produced from different pyrolysis environment. However, pyrolysis demonstrated a higher permeance under the gas environment due to lower membrane pore shrinkage and lower kinetic diameter, He: 2.60Å. In addition, gas permeability will reduce as the molecular size of the gas increases with the molecular sieve capacity.

The factors of carrying out carbon membrane with higher thermal soaking time is to allow pores resembles to $\mathrm{CM}-\mathrm{N}_{2}$ and $\mathrm{CM}-\mathrm{He}, \mathrm{CM}-\mathrm{Ar}$ had higher gas selectivity. This is due to, under the environment of Ar pyrolysis consists of less weight loss while under $N_{2}$ environment pyrolysis tends to quicken the pyrolysis with higher temperatures. The pyrolysis method under environment of $\mathrm{Ar}$ would be used for more analytical method involves considering the efficiency of gas separation and its physicochemical properties [10]. The effect of pyrolysis conditions on $\mathrm{PI} / \mathrm{NCC}$ carbon membrane (pyrolysis environment) was investigated from this research. Mixing nanocrystalline cellulose (NCC) into BTDA-TDI / MDI (P-84) polyimide was used to obtain carbon membranes with superior gas 
separation efficiency. Study into the conditions of pyrolysis showed the effect of pyrolysis environment on the morphology of the membrane and the ability to differentiate. Membrane prepared under the Argon environment encountered less weight decreasing while exhibiting the highest selectivity towards all the tested gas pairs compared to counterparts determined underneath the environment of, $\mathrm{He}$ and $\mathrm{N}_{2}$.

Table 1

Oxygen performance of carbon membranes produced from different pyrolysis environment

\begin{tabular}{llll}
\hline Samples & \multicolumn{2}{c}{ Permeance (GPU) } & \multicolumn{1}{c}{ Selectivity } \\
\cline { 2 - 4 } & \multicolumn{1}{c}{$\mathbf{O}_{2}$} & \multicolumn{1}{c}{$\mathbf{N}_{2}$} & $\mathbf{O}_{2} / \mathbf{N}_{2}$ \\
\hline CM- $\mathbf{N}_{2}$ & $15.1 \pm 2.8$ & $2.2 \pm 1.4$ & $6.9 \pm 2.4$ \\
CM-He & $24.0 \pm 1.2$ & $3.0 \pm 3.7$ & $8.0 \pm 2.6$ \\
CM-Ar & $26.5 \pm 3.3$ & $3.2 \pm 3.2$ & $8.3 \pm 2.5$
\end{tabular}

The factors of carrying out carbon membrane with higher thermal soaking time is to allow pores resembles to $\mathrm{CM}-\mathrm{N}_{2}$ and $\mathrm{CM}-\mathrm{He}, \mathrm{CM}-\mathrm{Ar}$ had higher gas selectivity. This is due to, under the environment of Ar pyrolysis consists of less weight loss while under $N_{2}$ environment pyrolysis tends to quicken the pyrolysis with higher temperatures. The pyrolysis method under environment of $\mathrm{Ar}$ would be used for more analytical method involves considering the efficiency of gas separation and its physicochemical properties [10]. The effect of pyrolysis conditions on PI/ NCC carbon membrane (pyrolysis environment) was investigated from this research. Mixing nanocrystalline cellulose (NCC) into BTDA-TDI / MDI (P-84) polyimide was used to obtain carbon membranes with superior gas separation efficiency. Study into the conditions of pyrolysis showed the effect of pyrolysis environment on the morphology of the membrane and the ability to differentiate. Membrane prepared under the Argon environment encountered less weight decreasing while exhibiting the highest selectivity towards all the tested gas pairs compared to counterparts determined underneath the environment of, $\mathrm{He}$ and $\mathrm{N}_{2}$.

\section{Conclusions}

He atmospheric pyrolysis gave a highly permeable membrane with a significantly lower selectivity than the carbon membrane equipped under Ar environment because of its high losing weight. In this study, membranes equipped under environment of $N_{2}$ environment and have the slightest attractive separation efficiency between the carbon membranes. The carbon membrane arranged under the Ar gas environment showed highest selectivity of $8.23 \pm 3.27$ for $\mathrm{O}_{2} / \mathrm{N}_{2} 213.56 \pm 2.17 \mathrm{GPU}$ permeance of $\mathrm{O}_{2}$. $\mathrm{PI} / \mathrm{NCC}$ membrane with its extremely promising gas separation efficiency, many applications may consider suitable like $\mathrm{CO}_{2}$ capture, $\mathrm{O}_{2}$ enrichment and $\mathrm{H}_{2}$ recovery.

\section{Acknowledgement}

Authors would like to extend their gratitude to Ministry of Higher Education Malaysia and Universiti Malaysia Pahang (UMP) with grant number RDU192315.

\section{References}

[1] Sazali, Norazlianie, Wan Norharyati Wan Salleh, Ahmad Fauzi Ismail, Nor Hafiza Ismail, and Kumaran Kadirgama. "A brief review on carbon selective membranes from polymer blends for gas separation performance." Reviews in Chemical Engineering 1, no. ahead-of-print (2019). 
https://doi.org/10.1515/revce-2018-0086

[2] Sanyal, Oishi, Stephanie T. Hicks, Nitesh Bhuwania, Samuel Hays, Manjeshwar G. Kamath, Shweta Karwa, Raja Swaidan, and William J. Koros. "Cause and effects of hyperskin features on carbon molecular sieve (CMS) membranes." Journal of Membrane Science 551 (2018): 113-122. https://doi.org/10.1016/i.memsci.2018.01.021

[3] He, Xuezhong. "Techno-economic feasibility analysis on carbon membranes for hydrogen purification." Separation and Purification Technology 186 (2017): 117-124.

https://doi.org/10.1016/i.seppur.2017.05.034

[4] Sazali, N., et al., CO2/CH4 Separation by Using Carbon Membranes. 2018. p. 209-234. https://doi.org/10.1016/B978-0-12-813645-4.00007-6

[5] Kim, Seong-Joong, Pyung Soo Lee, Jong-San Chang, Seung-Eun Nam, and You-In Park. "Preparation of carbon molecular sieve membranes on low-cost alumina hollow fibers for use in $\mathrm{C} 3 \mathrm{H} 6 / \mathrm{C} 3 \mathrm{H} 8$ separation." Separation and Purification Technology 194 (2018): 443-450.

[6] Kamath, Manjeshwar G., Shilu Fu, Arun K. Itta, Wulin Qiu, Gongping Liu, Raja Swaidan, and William J. Koros. "6FDADETDA: DABE polyimide-derived carbon molecular sieve hollow fiber membranes: Circumventing unusual aging phenomena." Journal of Membrane Science 546 (2018): 197-205. https://doi.org/10.1016/i.memsci.2017.10.020

[7] Su, Jincai, and Aik Chong Lua. "Effects of carbonisation atmosphere on the structural characteristics and transport properties of carbon membranes prepared from Kapton ${ }^{\circledR}$ polyimide." Journal of Membrane Science 305, no. 1-2 (2007): 263-270. https://doi.org/10.1016/i.memsci.2007.08.010

[8] Suda, Hiroyuki, and Kenji Haraya. "Gas permeation through micropores of carbon molecular sieve membranes derived from Kapton polyimide." The Journal of Physical Chemistry B 101, no. 20 (1997): 3988-3994.

https://doi.org/10.1021/ip963997u

[9] Geiszler, Vincent C., and William J. Koros. "Effects of polyimide pyrolysis conditions on carbon molecular sieve membrane properties." Industrial \& engineering chemistry research 35, no. 9 (1996): 2999-3003. https://doi.org/10.1021/ie950746j

[10] Ismail, N. H., W. N. W. Salleh, N. Sazali, A. F. Ismail, N. Yusof, and F. Aziz. "Disk supported carbon membrane via spray coating method: Effect of carbonization temperature and atmosphere." Separation and Purification Technology 195 (2018): 295-304.

https://doi.org/10.1016/j.seppur.2017.12.032

[11] Sazali, N., W. N. W. Salleh, A. F. Ismail, K. Kadirgama, and F. E. C. Othman. "P84 co-polyimide based-tubular carbon membrane: effect of heating rates on helium separations." In Solid State Phenomena, vol. 280, pp. 308-311. Trans Tech Publications Ltd, 2018. https://doi.org/10.4028/www.scientific.net/SSP.280.308

[12] Sazali, N., W. N. W. Salleh, N. Arsat, Z. Harun, and K. Kadirgama. "P84 Co-Polyimide-based tubular carbon membrane: effect of pyrolysis temperature." Journal of Applied Membrane Science \& Technology 23, no. 1 (2019). https://doi.org/10.11113/amst.v23n1.121

[13] Favvas, E. P., E. P. Kouvelos, G. E. Romanos, G. I. Pilatos, A. Ch Mitropoulos, and N. K. Kanellopoulos. "Characterization of highly selective microporous carbon hollow fiber membranes prepared from a commercial co-polyimide precursor." Journal of Porous Materials 15, no. 6 (2008): 625-633. https://doi.org/10.1007/s10934-007-9142-2

[14] Mohamed, M. A., W. N. W. Salleh, J. Jaafar, S. E. A. M. Asri, and A. F. Ismail. "Physicochemical properties of "green" nanocrystalline cellulose isolated from recycled newspaper." Rsc Advances 5, no. 38 (2015): 29842-29849. https://doi.org/10.1039/C4RA17020B

[15] Sazali, N., et al., Controlled Dip-coating Times for Improving CO2 Selective of PI/NCCbased Supported Carbon Membrane. Vol. 08. 2018. https://doi.org/10.4172/2155-9589.1000178

[16] Sazali, N., W. N. W. Salleh, A. F. Ismail, N. H. Ismail, Mohamad Azuwa Mohamed, N. A. H. M. Nordin, M. N. M. M. Sokri, Y. Iwamoto, and S. Honda. "Enhanced gas separation performance using carbon membranes containing nanocrystalline cellulose and BTDA-TDI/MDI polyimide." Chemical Engineering Research and Design 140 (2018): 221-228. https://doi.org/10.1016/i.cherd.2018.09.039

[17] Sazali, N., W. N. W. Salleh, and A. F. Ismail. "Carbon tubular membranes from nanocrystalline cellulose blended with P84 co-polyimide for H2 and He separation." international journal of hydrogen energy 42, no. 15 (2017): 9952 9957.

https://doi.org/10.1016/j.ijhydene.2017.01.128 
[18] Sazali, Norazlianie, Wan Norhayati Wan Salleh, Ahmad Fauzi Ismail, Kumaran Kadirgama, Mahendran Samykano, Gholamhassan Najafi, and Nur Izwanne Mahyon. "PI/NCC-Based Tubular Carbon Membrane: Influence of Aging Times Towards Oxygen Separation Performance." membranes 51, no. 2 (2018): 187-196.

[19] Ali, Akbar, Ramyakrishna Pothu, Sajid Hussain Siyal, Shahnawaz Phulpoto, Muhammad Sajjad, and Khalid Hussain Thebo. "Graphene-based membranes for CO2 separation." Materials Science for Energy Technologies 2, no. 1 (2019): 83-88. https://doi.org/10.1016/i.mset.2018.11.002

[20] Sazali, N., W. N. W. Salleh, A. F. Ismail, K. C. Wong, and Y. Iwamoto. "Exploiting pyrolysis protocols on BTDATDI/MDI (P84) polyimide/nanocrystalline cellulose carbon membrane for gas separations." Journal of Applied Polymer Science 136, no. 1 (2019): 46901.

https://doi.org/10.1002/app.46901

[21] Lu, G. Q., JC Diniz Da Costa, Mikel Duke, S. Giessler, R. Socolow, R. H. Williams, and T. Kreutz. "Inorganic membranes for hydrogen production and purification: a critical review and perspective." Journal of colloid and interface science 314, no. 2 (2007): 589-603.

https://doi.org/10.1016/i.jcis.2007.05.067

[22] Hu, Tianmiao, Hangyue Zhou, Hui Peng, and Heqing Jiang. "Nitrogen production by efficiently removing oxygen from air using a perovskite hollow-fiber membrane with porous catalytic layer." Frontiers in chemistry 6 (2018): 329.

https://doi.org/10.3389/fchem.2018.00329

[23] Favvas, Evangelos P., George Em Romanos, Fotios K. Katsaros, Konstantinos L. Stefanopoulos, Sergios K. Papageorgiou, Athanasios Ch Mitropoulos, and Nick K. Kanellopoulos. "Gas permeance properties of asymmetric carbon hollow fiber membranes at high feed pressures." Journal of Natural Gas Science and Engineering 31 (2016): 842-851. https://doi.org/10.1016/i.jngse.2016.03.089 